\title{
Информационно-аналитическое обеспечение управления финансовыми результатами экономического субъекта
}

\author{
И. В. Полухина ${ }^{1 凶}$ \\ ${ }^{1}$ Воронежский государственный университет, Университетская пл., 1, \\ 394018, Воронеж, Российская Федерация
}

Для цитирования: Полухина И. В. Информационно-аналитическое обеспечение управления финансовыми результатами экономического субъекта // Вестник Воронежского государственного университета. Серия: Экономика и управление. 2020. № 2. С. 90-104. DOI: 10.17308/econ.2020.2/2904

Предмет. Финансовые результаты являются значимым показателем в оценке эффективности финансово-хозяйственной деятельности, позволяют оценить, насколько были оправданы принятые компанией риски, прибыль создает финансовую основу для развития организации, обеспечения рыночной конкурентоспособности, реализации возможностей исполнения социальных корпоративных обязательств перед работниками и прироста стоимости бизнеса в интересах ее собственников. Проведение своевременного анализа доходов, расходов и факторной оценки финансовых результатов позволит в настоящих условиях принимать взвешенные управленческие решения, направленные на максимизацию доходной и минимизацию расходной составляющей для обеспечения успешной работы компании.

Цели. Комплексное авторское исследование проблемы анализа финансовых результатов коммерческой организации, выступающих гарантом обеспечения ее долгосрочного развития на рынке, неотъемлемым компонентом устойчивости и ключевым направлением в системе комплексного экономического анализа деятельности.

Методология. Автор раскрывает значение и содержание финансовых результатов и его компонентов, проводит сравнительный анализ подходов к сущности, систематизирует информационную базу, используя накопленный практический опыт. Грамотная и адресная работа в области аналитической поддержки принятия взвешенных управленческих решений по использованию финансовых и нефинансовых ресурсов позволят обеспечить желаемые показатели прибыли. В процессе исследования проблемы применялись методы логического, сравнительного анализа, поиска и систематизации.

Результаты. Раскрыты теоретические положения анализа финансовых результатов, приведен сравнительный анализ сущности финансовых результатов, систематизированы информационные и нормативные источники, раскрыто их содержание и особенности применения на практике, обобщены экономические интересы пользователей.

Выводы. Достижение положительного финансового результата (прибыли) - центральное направление работы топ-менеджмента организации и результат успешной текущей, инвестиционной и финансовой деятельности. Однако в условиях конкуренции организация не застрахована от получения убытков. Они показывают ошибки руководства в направлениях использования материально-вещественных и денежных активов. В связи с этим особую значимость составляет рациональное управление доходами и расходами. От качества информационной базы напрямую зависит достоверность аналитических выводов, лежащих в основе принятия взвешенных управленческих решений. При проведении анализа финансовых результатов крайне важно учитывать экономические интересы пользователей, заинтересованных в его результатах. Это позволит выбрать группу ключевых показателей оценки эффективности деятельности организации и оптимально распределить ресурсы.

Ключевые слова: доходы и расходы, прибыль (убыток), эффективность деятельности, устойчивость организации, экономический анализ.

\section{Введение}

Современные бизнес-условия, в которых существуют подавляющее большинство рос-

(C) Полухина И. В., 2020

Вестник ВГУ. Серия: Экономика и управление. 2020. № 2. С. 90-104. сийских и зарубежных компаний, характеризуются острой конкурентной борьбой, динамичностью развития технологий, нестабильностью на рынках, изменением политики на 
Информационно-аналитическое обеспечение управления финансовыми результатами...

территории страны размещения основных и вспомогательных производств, изменением налоговой, денежно-кредитной и социальной обстановки. Новые, порой крайне сложно предсказуемые экономические, экологические и социальные условия вынуждают экономические субъекты управлять изменениями, внедрять передовые инструменты и технологические решения, искать резервы повышения эффективности использования ограниченных ресурсов, пересматривать (корректировать) стратегию развития бизнеса на среднесрочную и долгосрочную перспективу. Российские компании с разным темпом внедряют изменения в управлении производством и финансовой составляющей деятельности. Считаем, что это прежде всего зависит от масштабов организации, ее выхода на зарубежные рынки и уровня конкуренции. Известные российские корпорации с мировым именем не могут жить изолированно и вынуждены отслеживать политику конкурентов, обеспечивать непрерывные улучшения, внедрять проекты бережливого производства для выживания в условиях конкуренции, эффективного вывода новых продуктов на рынки, экономного и эффективного использования имеющихся ресурсов, грамотного управления материально-вещественными и денежными (финансовыми) потоками. Конечной целью деятельности любой коммерческой организации вне зависимости от ее формы устройства и собственности является получение положительного финансового результата в целом и по направлениям деятельности, видам производимой продукции (выполняемых работ, оказываемых услуг).

Финансовые результаты являются одним из ключевых показателей в оценке эффективности финансово-хозяйственной деятельности компании, позволяют оценить, насколько были оправданы принятые компанией финансовые и нефинансовые риски, прибыль создает финансовую основу для развития организации, исполнения инвестиционных проектов, дополнительных социальных выплат сотрудникам, прироста выплат дивидендов акционерам и является гарантированным источником пополнения резервного фонда. Налог на прибыль, который уплачивают компании, является источником пополнения доходов государства, поэтому крайне важно для стабильного развития экономики присутствие эффективных экономических субъектов. В связи с этим качество формирования доходов, расходов и финансовых результатов выступает приоритетной задачей учета, а аналитическое обеспечение принятия управленческих решений центральной задачей анализа организации. На протяжении последних лет прибыль, как важнейшая экономическая категория, получила свое новое наполнение в условиях современного экономического развития нашей страны, в формировании реальной самостоятельности субъектов хозяйствования. В связи с этим важно понимать доступные инструменты и методы экономического анализа, способствующие выявлению влияющих факторов, дающие оценку резервов повышения эффективности хозяйствования.

Высокая теоретико-практическая значимость обеспечила интерес к учетно-аналитическим проблемам финансовых результатов многих российских ученых-экономистов. Особый вклад в развитие учетно-аналитических вопросов внесли В. В. Бочаров, В. Р. Банк, Л. Т. Гиляровская, Д. А. Ендовицкий, О. В. Ефимова, В. В. Ковалев, Н. П. Любушин, М. В. Мельник, Т. А. Пожидаева, Г. В. Савицкая, Р. С. Сайфулин, Ю. Бригхем, А. Д. Шеремет и др.

Вместе с тем ряд организационных и методических вопросов экономического анализа финансовых результатов остается нерешенным до сих пор. Речь идет, например, о систематизации пользователей результатов экономического анализа финансовых результатов и обособлении их экономических интересов, обобщении нормативно-правовых источников и информационной базы в условиях постоянно меняющейся рыночной экономики и нормативных требований, необходимости определения этапов проведения такого анализа в соответствии с практическими потребностями компании. Это свидетельствует об актуальности и практической значимости избранной темы исследования, что повлияло на выбор цели, определение задач и периметра рассматриваемых проблем.

Таким образом, для принятия взвешенных решений руководству организации необходимо обладать всесторонней своевременной информацией о состоянии доходов, расходов и достижении целевых показателей финансовых результатов коммерческой организации. 
Достичь этого возможно, проводя своевременный мониторинг и экономический анализ на основе комплексного и системного подходов, способствующих установлению проблемных областей, выявлению резервов для роста доходов и минимизации расходов организации, оценке рентабельности деятельности и продукции. Чтобы обеспечить исполнение заявленной цели в исследовании, необходимо последовательно решить следующие задачи. Во-первых, разобраться с сущностью понятия финансовых результатов применительно к настоящим условиям ведения бизнеса. Во-вторых, определить роль экономического анализа и его ключевые направления по оценке доходов, расходов и результатов, а также обобщить нормативно-правовую и информационную базу. В-третьих, систематизировать заинтересованных пользователей анализа финансовых результатов и их экономические интересы.

\section{Материалы и методы исследования}

Итогом многосторонней деятельности, направленной на повышение эффективности использования имеющихся ресурсов каждого хозяйствующего субъекта, является достижение определенных финансовых результатов: прибыли или убытка. Вне сомнения, желаемый результат - получение прибыли. Она создает базу для расширения производства, реализации инвестиционных проектов, выступает гарантом долгосрочной деятельности, обеспечивает дополнительные ресурсы для социального обеспечения интересов сотрудников. Кроме того, получение прибыли означает, что предпринятые усилия по преодолению рисков были оправданы. Но отметим, что в реальной жизни организация не застрахована от получения убытков. Они показывают ошибки менеджмента в направлениях координации расходной и доходной составляющей финансовых результатов. Таким образом, финансовые результаты являются индикатором эффективности всех активных и пассивных операций компании, возможности грамотно управлять рисками и преодолевать вызовы как экономического, так и рыночного характера. В литературе часто можно встретить подходы к определению финансовых результатов в двух направлениях: нормативно-правовом и авторских. Для понимания, в чем состоит сущность финансовых результатов, мы систематизировали ключевые авторские российские (табл. 1) и зарубежные подходы (табл. 2).

Т а бли ц а 1

Анализ подходов отечественных ученых-экономистов к определению финансовых результатов как объекта экономического анализа

\begin{tabular}{|c|c|c|}
\hline $\begin{array}{c}\text { Ключевая } \\
\text { характеристика }\end{array}$ & $\begin{array}{l}\text { Авторы } \\
\text { подхода }\end{array}$ & Экономическая сущность подхода \\
\hline $\begin{array}{l}\text { Чистый доход } \\
\text { и основа рен- } \\
\text { табельности }\end{array}$ & Г. В. Савицкая & $\begin{array}{l}\text { Прибыль понимается через компонент чистого дохода, получа- } \\
\text { емого организацией после продажи продукции. Здесь же дается } \\
\text { определение рентабельности: «показатели рентабельности харак- } \\
\text { теризуют эффективность работы в целом и, более чем прибыль, } \\
\text { отражают окончательные результаты хозяйствования, потому } \\
\text { что их величина показывает соотношение эффекта с наличными } \\
\text { или использованными ресурсами» [12]. Чистый доход принимает } \\
\text { форму прибыли только в случае продажи продукци. Финансовые } \\
\text { результаты находятся в тесной связи с продажей продукции }\end{array}$ \\
\hline $\begin{array}{c}\text { Награда за } \\
\text { принятый риск }\end{array}$ & Н. Н. Селезнева & $\begin{array}{l}\text { Чистый доход на вложенный капитал, награда за риск предпри- } \\
\text { нимательской деятельности [14] }\end{array}$ \\
\hline $\begin{array}{l}\text { Конечная цель } \\
\text { развития любого } \\
\text { бизнеса } \\
\end{array}$ & Л. Т. Гиляровская & $\begin{array}{l}\text { Особый ресурс, систематически воспроизводимый коммерче- } \\
\text { ской организацией, конечная цель развития любого бизнеса [4] }\end{array}$ \\
\hline $\begin{array}{c}\text { Конечный } \\
\text { результат } \\
\text { деятельности }\end{array}$ & $\begin{array}{l}\text { А. Д. Шеремет, } \\
\text { Р. С. Сайфулин }\end{array}$ & $\begin{array}{l}\text { Балансовая прибыль (убыток) отчетного периода, представ- } \\
\text { ляющая собой алгебраическую сумму результата от продажи } \\
\text { продукции, результата от финансовой деятельности, сальдо } \\
\text { доходов и расходов от прочих операций [18; 19] }\end{array}$ \\
\hline $\begin{array}{c}\text { Финансовая } \\
\text { результатив- } \\
\text { ность осущест- } \\
\text { вляемых видов } \\
\text { деятельности }\end{array}$ & Н.А.Бреславцева & $\begin{array}{l}\text { Требуется обобщающий показатель глобальной финансовой } \\
\text { результативности, который бы отражал состояние имуще-- } \\
\text { ства и динамику капитала, предоставлял целостную картину. } \\
\text { Позволит понять, исчислить, проанализировать и исследовать } \\
\text { следующие явления и процессы: управление рыночной капи- } \\
\text { тализацией; образование прибыли; наполнение финансового } \\
\text { результата; подкрепление денежным потоком и др. [3] }\end{array}$ \\
\hline
\end{tabular}


Информационно-аналитическое обеспечение управления финансовыми результатами...

Т а блиц а 2

Анализ подходов зарубежных ученых-экономистов к определению прибыли

\begin{tabular}{|c|c|c|}
\hline $\begin{array}{c}\text { Ключевая } \\
\text { характеристика }\end{array}$ & Авторы подхода & Экономическая сущность подхода \\
\hline \multirow{3}{*}{$\begin{array}{l}\text { Прибыль- } \\
\text { прибавочный } \\
\text { продукт, получа- } \\
\text { емый в торговле }\end{array}$} & Т. Мен, Д. Локк & $\begin{array}{l}\text { Предприняли одними из первых попытку пояснить источник } \\
\text { образование прибыли, основываясь на теории меркантилистов } \\
\text { XVI-XVII вв. Считали, что прибыль образовывается в результате } \\
\text { внешнеторговых действий, когда люди продают товары за гра- } \\
\text { ницей по более высоким ценам, чем они их купили [15] }\end{array}$ \\
\hline & $\begin{array}{l}\text { Д. Рикардо, } \\
\text { А. Смит }\end{array}$ & $\begin{array}{l}\text { Д. Рикардо вывел закон, где заработная плата и прибыль находят- } \\
\text { ся в обратном отношении друг к другу. Прибыль будет высока или } \\
\text { низка в соответствии с тем, низка или высока заработная плата. } \\
\text { А. Смит обозначал, что стоимость, которую рабочие прибавляют к } \\
\text { стоимости материалов, делится на два компонента. Первый идет } \\
\text { на оплату труда, второй - это прибыль предпринимателя }\end{array}$ \\
\hline & К. Маркс & $\begin{array}{l}\text { Определял через трактовку неоплаченного труда наемных рабо- } \\
\text { чих. Это вторичная, производная и трансформированная форма } \\
\text { прибавочной стоимости }\end{array}$ \\
\hline $\begin{array}{c}\text { Вознаграждение } \\
\text { за риск }\end{array}$ & $\begin{array}{l}\text { Ф. Найт, } \\
\text { Э. Чемберлин, } \\
\text { Д. Робинсон }\end{array}$ & $\begin{array}{l}\text { Отмечают, что происхождение прибыли находится в тесной свя- } \\
\text { зи с предпринимательством и риском деятельности. В периме- } \\
\text { тре ограничиваются состоянием совершенной конкуренции и не } \\
\text { учитывают фактор образований монополий. } \\
\text { Позднее в трудах Д. Робинсона, Э. Чемберлина появляются мыс- } \\
\text { ли «теории монополистической конкуренции» }\end{array}$ \\
\hline $\begin{array}{l}\text { Прибыль как } \\
\text { источник про- } \\
\text { цента на вло- } \\
\text { женный капитал }\end{array}$ & $\begin{array}{l}\text { О. Бем-Баверк, } \\
\text { Й. Шумпетер, } \\
\text { Ф. Уокер }\end{array}$ & $\begin{array}{l}\text { Обозначили, что прибыль - это отдельная форма дохода. Она отли- } \\
\text { чается от процента, является наградой за риск предпринимателя. } \\
\text { Й. Шумпетер в своей теории данное направление развил. Предпри- } \\
\text { нимательская прибыль понимается как избыток сверх-издержек } \\
\text { производства, разница между выручкой и затратами. В дальней- } \\
\text { шем данная идея была развита в работах Ф. Уокера [2] }\end{array}$ \\
\hline $\begin{array}{l}\text { Источник благо- } \\
\text { состояния обще- } \\
\text { ства и индивида }\end{array}$ & Д. Хикс & $\begin{array}{l}\text { Утверждает, что необходимо рассказать людям о прибыли, т. е. } \\
\text { сумме, которую они могут использовать на потребление, не } \\
\text { уменьшая свое благосостояние (не становясь беднее). Доход } \\
\text { (прибыль) человека есть максимальная сумма, которую он мо- } \\
\text { жет расходовать в течение определенного периода времени }\end{array}$ \\
\hline
\end{tabular}

Анализ научной литературы показал, что данные авторы подходят к определению категории «финансовые результаты» с различных позиций и разной степенью детализации. Представляется интересным подход экономиста Я. В. Соколова: «...считается, что прибыль необходима для: оценки эффективности работы фирмы (чем больше прибыль, тем лучше работа); определения величины налогооблагаемой базы (чем меньше прибыль, тем меньше налоговые платежи); принятия решений, связанных с вложением средств в фирму, покупкой ее акций (чем больше прибыль, тем выгоднее держать ее акции); достижения цели собственников-акционеров (чем больше прибыль, тем выше курс фирмы, тем богаче ее держатель)» [11].

В соответствии с Положением по бухгалтерскому учету России (далее - ПБУ) 9/99 «Доходы организации» признается доходами увеличение экономических выгод в результате поступления активов (денежных средств, иного имущества) и (или) погашения обязательств, приводящее к росту капитала этой организации, за исключением вкладов участников (собственников имущества)». МСФО 18 «Выручка» определяет доход как валовое поступление экономических выгод за определенный период в ходе обычной деятельности предприятия, приводящее к увеличению капитала, не связанного с взносами участников капитала [16]. Доходы организации подразделяются на доходы от обычных видов деятельности и прочие. В соответствии с ПБУ 9/99 выручка признается в бухгалтерском учете при соблюдении следующих пяти условий. В системе международного учета и отчетности самостоятельного нормативного документа по расходам нет. Расходами организации признается уменьшение экономических выгод в результате выбытия активов (денежных средств, иного имущества) и (или) возникновения обязательств, приводящее к уменьшению 
капитала этой организации, за исключением уменьшения вкладов по решению участников (собственников имущества). Расходы организации в зависимости от их характера, условий осуществления и направлений деятельности организации подразделяются на расходы по обычным видам деятельности; прочие расходы. В мировой практике расходы возникают, если происходит уменьшение будущих экономических выгод, связанных с уменьшением актива или увеличением обязательства, которые могут быть надежно измерены. Следует признать, что российский стандарт ПБУ 10/99 содержит более жесткие критерии признания. В отличие от МСФО расход в соответствии с ПБУ 10/99 не может быть признан только на основании профессионального суждения бухгалтера об уменьшении экономических выгод и должен подтверждаться документально: договором, нормативом и т. п. Это требование ограничивает российские организации и не позволяет учесть все операции, относящиеся к определенному периоду. Различия в сроках учета операций приводят к расхождениям в учетах. ПБУ не учитывают инфляцию, в МСФО отдается приоритет правдивому отражению хозяйственной жизни [13].

Таким образом, финансовый результат это комплексное понятие, определяется как совместный результат от текущей, инвестиционной и финансовой деятельности. Он выражается в виде выручки от продажи продукции (работ, услуг), а также в виде чистой прибыли (убытка). Финансовый результат определяется как разность доходов и расходов в разрезе видов деятельности и компании в целом.

Учет обеспечивает формирование информационной базы последующего анализа в виде данных внешней отчетности и управленческих отчетов. Нормативная база, регулирующая правила учета финансовых результатов и распределения прибыли коммерческих организаций, приведена в табл. 3, 4. Состав, содержание и качество информации, которая привлекается к анализу, играют определяющую роль в обеспечении точности и полноты аналитических заключений, принятия руководством оптимальных организационных решений.

Наиболее полезными для пользователей являются данные, полученные из управлен- ческого учета и нормативно-плановых показателей. Эта информация обладает высокой степенью оперативности, может быть визуализирована по различным признакам: видам деятельности, структурным подразделениям, сегментам и др. Информация, извлекаемая из бухгалтерской отчетности в годовом или квартальном формате, такими качествами не обладает.

Представим характеристику основных источников данных для анализа финансовых результатов коммерческой организации (табл. 5).

Данные годовой отчетности имеют агрегированный характер и отражают результат деятельности организации в целом, причем за довольно продолжительный период времени. Состояние доходов и расходов в течение отчетного периода может существенно отличаться от отраженного в отчетности. Порядок формирования информации в управленческом учете определяется организацией самостоятельно, исходя из внутренних потребностей, и может предполагать предоставление аналитики за любой необходимый период. Поэтому сложно представить унифицированно описание алгоритмов аналитических расчетов при исследовании доходов и расходов организации, ориентируясь на возможную учетную информацию. С другой стороны, опираясь на данные публичной отчетности, можно провести сравнительный и трендовый анализ нескольких компаний [6;7]. Унифицированность показателей, раскрываемых в отчетности, высокая достоверность данных позволяют принимать отдельные решения. Информация этой отчетности доступна не только внутренним, но и внешним пользователям. Ориентация на такую информацию позволяет разработать унифицированное методическое обеспечение анализа финансовых результатов организации, которое может применяться в разных организациях и при внутреннем, и при внешнем анализе.

Оперативность получения отчетных показателей без дополнительных трудовых и временных затрат не только по году (кварталу), но и чаще является важной составляющей повышения качества анализа финансовых результатов. 
Информационно-аналитическое обеспечение управления финансовыми результатами...

Верхнеуровневая систематизация нормативных источников учета

\begin{tabular}{|c|c|}
\hline Наименование источника & Характер регулирования \\
\hline Федеральные законы РФ & \multirow{3}{*}{$\begin{array}{l}\text { Регулируются нормативно-правовые основы бухгалтерского учета, на- } \\
\text { правления деятельности, содержание, принципы, порядок составления } \\
\text { и предоставления отчетности }\end{array}$} \\
\hline Указы Президента РФ & \\
\hline $\begin{array}{c}\text { Постановления } \\
\text { Правительства РФ } \\
\end{array}$ & \\
\hline $\begin{array}{l}\text { Федеральные правила } \\
\text { (стандарты) }\end{array}$ & $\begin{array}{l}\text { Устанавливают требования к учетной политике, документообороту и пер- } \\
\text { вичным учетным документам, раскрывают счета бухгалтерского учета, } \\
\text { порядок применения, упрощенные способы ведения учета }\end{array}$ \\
\hline Отраслевые стандарты & $\begin{array}{l}\text { Устанавливают особенности применения федеральных стандартов в от- } \\
\text { дельных видах экономической деятельности }\end{array}$ \\
\hline $\begin{array}{l}\text { Рекомендации в } \\
\text { бухгалтерского } \\
\end{array}$ & $\begin{array}{l}\text { Принимаются в целях правильного применения федеральных и отрасле- } \\
\text { вых стандартов, применение носит добровольный характер }\end{array}$ \\
\hline $\begin{array}{l}\text { Стандарты экономиче- } \\
\text { ского субъекта }\end{array}$ & $\begin{array}{l}\text { На уровне организации принимается решение по разработке индивиду- } \\
\text { альных стандартов, исключительно по собственному усмотрению. В слу- } \\
\text { чае их издания носят обязательный характер для внутренних структур- } \\
\text { ных подразделений }\end{array}$ \\
\hline
\end{tabular}

Нормативные документы, оказывающие влияние на формирование

Т а бли ц а 4 финансовых результатов в учете и отчетности

\begin{tabular}{|c|c|c|c|}
\hline Наименование нормативного акта & Номер, год принятия & $\begin{array}{l}\text { Номер } \\
\text { приказа }\end{array}$ & $\begin{array}{c}\text { Дата } \\
\text { принятия }\end{array}$ \\
\hline $\begin{array}{l}\text { Положение по ведению бухгалтерского учета } \\
\text { и бухгалтерской отчетности в РФ }\end{array}$ & 1998 & № $34 \mathrm{H}$ & 29.07.1998 \\
\hline Учетная политика организации & ПБУ 1/2008 & № $106 \mathrm{H}$ & 06.01 .2008 \\
\hline Учет договоров строительного подряда & ПБУ 2/2008 & № $116 \mathrm{H}$ & 24.10 .2008 \\
\hline $\begin{array}{l}\text { Учет активов и обязательств, стоимость которых } \\
\text { выражена в иностранной валюте }\end{array}$ & ПБУ 3/2006 & № $154 \mathrm{H}$ & 27.11.2006 \\
\hline Бухгалтерская отчетность организации & ПБУ 4/99 & № $43 \mathrm{H}$ & 06.07.1999 \\
\hline Учет материально-производственных запасов & ПБУ 5/01 & № $44 \mathrm{H}$ & 09.06.2001 \\
\hline Учет основных средств & ПБУ 6/01 & № $26 \mathrm{H}$ & 30.03.2001 \\
\hline События после отчетной даты & ПБУ 7/98 & № $56 \mathrm{H}$ & 25.11 .1998 \\
\hline $\begin{array}{l}\text { Оценочные обязательства, условные обязательства } \\
\text { и условные активы }\end{array}$ & ПБУ 8/2011 & № $167 \mathrm{H}$ & 13.12.2011 \\
\hline Доходы организации & ПБУ 9/99 & № $32 \mathrm{H}$ & 06.05 .1999 \\
\hline Расходы организации & ПБУ 10/99 & № $33 \mathrm{H}$ & 06.05 .1999 \\
\hline Информация о связанных сторонах & ПБУ $11 / 2008$ & № $48 \mathrm{H}$ & 29.04.2008 \\
\hline Информация по сегментам & ПБУ 12/2011 & № $143 \mathrm{H}$ & 08.11 .2011 \\
\hline Учет государственной помощи & ПБУ 13/2000 & № $92 \mathrm{H}$ & 16.10 .2000 \\
\hline Учет нематериальных активов & ПБУ 14/2007 & № $153 \mathrm{H}$ & 27.12 .2007 \\
\hline Учет расходов по займам и кредитам & ПБУ $15 / 2008$ & № $107 \mathrm{H}$ & 06.10 .2008 \\
\hline Информация по прекращаемой деятельности & ПБУ 16/02 & № $66 \mathrm{H}$ & 02.07.2002 \\
\hline $\begin{array}{l}\text { Учет расходов на научно-исследовательские, } \\
\text { опытно-конструкторские и технологические работы }\end{array}$ & ПБУ 17/02 & № $115 \mathrm{H}$ & 19.11.2002 \\
\hline Учет расчетов по налогу на прибыль & ПБУ 18/02 & № $114 \mathrm{H}$ & 19.11.2002 \\
\hline Учет финансовых вложений & ПБУ 19/02 & № $126 \mathrm{H}$ & 10.12.2002 \\
\hline Информация об участии в совместной деятельности & ПБУ 20/03 & № $105 \mathrm{H}$ & 24.11 .2003 \\
\hline Изменение оценочных значений & ПБУ $21 / 2008$ & № $106 \mathrm{H}$ & 06.10 .2008 \\
\hline Исправление ошибок в учете и отчетности & ПБУ 22/2011 & № $63 \mathrm{H}$ & 28.06.2011 \\
\hline Отчет о движении денежных средств & ПБУ 23/2012 & № $11 \mathrm{H}$ & 02.02 .2012 \\
\hline Учет затрат на освоение природных ресурсов & ПБУ 24/2012 & № $125 \mathrm{H}$ & 06.11 .2012 \\
\hline
\end{tabular}


Информационная база анализа финансовых результатов организации

\begin{tabular}{|c|c|}
\hline Источник информации & $\begin{array}{c}\text { Содержание информации для целей } \\
\text { анализа финансовых результатов }\end{array}$ \\
\hline 1 & 2 \\
\hline \multicolumn{2}{|c|}{ Блок 1. Информациия бухгалтерского учета } \\
\hline Аналитика и отчеты Главной книги & Содержит данные оборотов по 90, 91, 99, 84, 20, 25, 26, 44 счетам \\
\hline $\begin{array}{l}\text { Управленческие сведения и анали- } \\
\text { тика к счетам бухгалтерского учета } \\
90 \text { (все субчета) «Продажи», 91 (все } \\
\text { субчета) «Прочие доходы и расходы», } \\
99 \text { (все субчета) «Прибыли и убытки», } \\
84 \text { (все субчета) «Нераспределенная } \\
\text { прибыль (непокрытый убыток)» }\end{array}$ & $\begin{array}{l}\text { 90-е и 91-е счета используются для консолидации инфор- } \\
\text { мации о доходах и расходах по обычным и прочим видам } \\
\text { деятельности организации, а также для определения финан- } \\
\text { совых результатов по ним; } \\
\text { 99-й счет необходим для обобщения информации о форми- } \\
\text { ровании конечного финансового результата деятельности } \\
\text { организации в отчетном году; } \\
\text { 84-й счет отражает информацию о наличии и движении не- } \\
\text { распределенной прибыли, непокрытого убытка }\end{array}$ \\
\hline $\begin{array}{l}\text { Управленческие сведения и ана- } \\
\text { литика к бухгалтерским счетам } 20 \\
\text { «Основное производство», } 25 \text { «Обще- } \\
\text { производственные расходы», счету } 44 \\
\text { «Расходы на продажу» }\end{array}$ & $\begin{array}{l}\text { На 20-х счетах обобщается информация о затратах на произ- } \\
\text { водство продукции (работы, услуги) по основному виду дея- } \\
\text { тельности организации; } \\
\text { 25-е счета используются для отражения данных о расходах } \\
\text { по обслуживанию основных и вспомогательных производств } \\
\text { организации; } \\
\text { 26-е счета - для обобщения информации о расходах для нужд } \\
\text { управления, не связанных непосредственно с производствен- } \\
\text { ным процессом; } \\
\text { 44-е счета предназначены для обобщения информации в } \\
\text { промышленных организациях об упаковке изделий на скла- } \\
\text { дах готовой продукции; по доставке продукции на станцию } \\
\text { (пристань) отправления, погрузке в вагоны, суда, автомобили } \\
\text { и другие транспортные средства; комиссионные сборы (отчис- } \\
\text { ления), уплачиваемые сбытовым и другим посредническим } \\
\text { организациям; по содержанию помещений для хранения про- } \\
\text { дукции в местах ее продажи и оплате труда продавцов в орга- } \\
\text { низациях, занятых сельскохозяйственным производством; на } \\
\text { рекламу; на представительские расходы }\end{array}$ \\
\hline $\begin{array}{l}\text { Регистры аналитического бухгалтер- } \\
\text { ского и налогового учета }\end{array}$ & $\begin{array}{l}\text { Содержат информацию, необходимую для детального анализа } \\
\text { финансовых результатов }\end{array}$ \\
\hline \multicolumn{2}{|c|}{ Блок 2. Первичные учетные документы (документы-основания) } \\
\hline $\begin{array}{l}\text { Накладная на отпуск материалов на } \\
\text { сторону }\end{array}$ & $\begin{array}{l}\text { Необходима для отражения выбытия материалов в результа- } \\
\text { те их продажи или иного выбытия }\end{array}$ \\
\hline Товарная накладная & $\begin{array}{l}\text { Отражает продажу (отпуск) товарно-материальных ценностей } \\
\text { сторонней организации }\end{array}$ \\
\hline Заказ - отборный лист & $\begin{array}{l}\text { Данная форма выполняет функцию заявки (заказа), она по- } \\
\text { зволяет вести расчеты по самостоятельным группам товаров }\end{array}$ \\
\hline Расходно-приходная накладная & Отражает отпуск товаров со склада кладовщиком \\
\hline Путевой лист & $\begin{array}{l}\text { Содержит информацию о материальных затратах на горюче- } \\
\text { смазочные материалы }\end{array}$ \\
\hline Акт приемки материалов & $\begin{array}{l}\text { Представляет информацию о приемке и оприходовании посту- } \\
\text { пающих материалов и тары }\end{array}$ \\
\hline $\begin{array}{l}\text { Табель учета рабочего времени и рас- } \\
\text { четы оплаты труда }\end{array}$ & $\begin{array}{l}\text { Требуется для учета времени, фактически отработанного и (или) } \\
\text { не отработанного каждым работником организации, и расчета } \\
\text { оплаты труда }\end{array}$ \\
\hline $\begin{array}{l}\text { Расчетно-платежная ведомость, расчет- } \\
\text { ная ведомость и платежная ведомость }\end{array}$ & $\begin{array}{l}\text { Применяются для расчета и выплаты заработной платы работ- } \\
\text { никам организации }\end{array}$ \\
\hline Лицевой счет & $\begin{array}{l}\text { Включает данные о начислениях и выплатах работникам зара- } \\
\text { ботной платы }\end{array}$ \\
\hline $\begin{array}{l}\text { Записка-расчет о предоставлении } \\
\text { отпуска работнику }\end{array}$ & $\begin{array}{l}\text { Применяется для расчета причитающейся заработной платы } \\
\text { и других выплат при предоставлении ежегодного оплачивае- } \\
\text { мого отпуска или иного отпуска и др. }\end{array}$ \\
\hline
\end{tabular}


Информационно-аналитическое обеспечение управления финансовыми результатами...

Окончание табл. 5

\begin{tabular}{|c|c|}
\hline 1 & 2 \\
\hline $\begin{array}{l}\text { Акт ввода в эксплуатацию объекта } \\
\text { основных средств }\end{array}$ & Отражает расходы, связанные с начислением амортизации \\
\hline $\begin{array}{l}\text { Инвентарная карточка учета объек- } \\
\text { тов основных средств и инвентарная } \\
\text { карточка группового учета объектов } \\
\text { основных средств }\end{array}$ & $\begin{array}{l}\text { Содержат ключевые данные по объекту основных средств (сро } \\
\text { полезного использования, способ начисления амортизации, } \\
\text { отметка о неначислении амортизации) }\end{array}$ \\
\hline $\begin{array}{l}\text { Товарно-транспортная накладная, } \\
\text { предназначена для учета движения } \\
\text { товарно-материальных ценностей и } \\
\text { расчеты за их перевозки автомобиль- } \\
\text { ным транспортом }\end{array}$ & $\begin{array}{l}\text { Предназначена для учета движения товарно-материальных } \\
\text { ценностей и расчеты за их перевозки автомобильным транс- } \\
\text { портом }\end{array}$ \\
\hline Договор и акт выполненных работ & $\begin{array}{l}\text { Отражает основные условия сделки (цена, сроки, момент пе- } \\
\text { рехода права собственности, права и обязанности сторон) }\end{array}$ \\
\hline $\begin{array}{l}\text { Данные экономического, финансового, } \\
\text { бюджетного отделов }\end{array}$ & $\begin{array}{l}\text { Содержит сведения о бюджете продаж, планируемых направ- } \\
\text { лениях поступления и использования денежных средств, до- } \\
\text { ходах и расходах }\end{array}$ \\
\hline
\end{tabular}

Блок 3. Бухгалтерская отчетность организации

Бухгалтерский баланс $\quad$ Раскрывает данные о нераспределенной прибыли (убытке), полученной в отчетном и прошлых периодах, отложенных обязательствах и активах, возникающих в результате постоянных и временных разниц

\begin{tabular}{l|l} 
Отчет о финансовых результатах & Содержит данные о выручке, производственной себестоимости,
\end{tabular} коммерческих и управленческих расходах, прибыли от продаж, прочих доходах и расходах, прибыли до налогообложения, налоге на прибыль, чистой прибыли, прибыли на акцию

Отчет о движении денежных средств Информация о движении денежных средств в разрезе текущей, инвестиционной и финансовой деятельности организации

\begin{tabular}{l|l} 
Отчет об изменениях капитала & Информация о движении уставного капитала, резервного
\end{tabular} капитала, дополнительного капитала, а также информация об изменениях величины нераспределенной прибыли (непокрытого убытка) организации. Кроме того, в этой форме указывают суммы резервов, которые были сформированы и (или) использованы организацией

Пояснения к бухгалтерской отчетности Раскрывают информацию о величине материальных затрат, затрат на оплату труда с отчислениями на социальные нужды, величину амортизации, отраслевых резервов, незавершенного производства, готовой продукции для перепродажи, составе и структуре прочих доходов и прочих расходов, расшифровки по объектам договоров строительного подряда и пр.

Блок 4. Статистическая отчетность организациии

№ 5-3 «Сведения о затратах на производство и продажу продукции (това- $\quad$ собственного производства, выполненных собственными ров, работ, услуг)» силами работах и услугах, продаже товаров несобственного производства, о затратах на производство и продажу продукции (товаров, работ, услуг), включая расходы на приобретение товаров для перепродажи

№ 1-предприятие «Основные сведе- $\quad$ Сведения о производстве и отгрузке товаров, работ и услуг, о ния о деятельности организации» проданном сырье, материалах, комплектующих изделиях, топливе и приобретенных ранее для производства продукции

Сведения о производстве и отгрузке товаров и услуг

Данные о выпуске товаров, услуг в фактических ценах, количестве отгруженной продукции, объеме и отгрузке продукции по отраслевому разрезу

Блок 5. Налоговая отчетность

Данные налоговых деклараций по налогу на прибыль

Позволяют определить величину налога на прибыль, отложенных активов и отложенных налоговых обязательств

Данные налоговых деклараций по прочим налогам, относящимся на себестоимость 
Таким образом, значительную роль в информационном обеспечении анализа играют бухгалтерский учет и отчетность, где наиболее полно отражаются хозяйственные явления, процессы, их результаты. Своевременный и полный анализ данных, которые содержатся в первичных и сводных учетных регистрах и отчетности, обеспечивает принятие необходимых корректирующих мер, направленных на достижение лучших результатов хозяйствования.

К организации информационного обеспечения анализа предъявляется ряд базовых требований: оперативность информации, сопоставимость, аналитичность, достоверность и другие. В противном случае выводы, сделанные по результатам проведенного экономического анализа, не будут соответствовать действительности [8].

Задачами анализа финансовых результатов современной организации являются систематический контроль формирования финансовых результатов; определение влияния как объективных, так и субъективных факторов на финансовые результаты; выявление резервов роста величины прибыли и рентабельности и прогнозирование их величины; разработка мероприятий по освоению выявленных резервов [5].

Анализ финансовых результатов деятельности организации включает в качестве обязательных элементов:

- динамическую оценку показателей;

- структурную оценку показателей прибыли и изменений их состава;

- изучение трендов изменения показателей за ряд периодов для выявления основных тенденций развития показателей: устойчивый рост, снижение или цикличный характер их проявления. На данном этапе может быть рассчитан средний темп прироста в абсолютном или относительном выражении - «тренд», на его основании возможен расчет прогнозируемой величины показателя следующего периода с помощью метода простой экстраполяции;

- идентификацию факторов и основополагающих причин изменения показателей прибыли и их количественную оценку [17].

Финансовые результаты можно оценить с помощью абсолютных и относительных показателей. Анализ формирования, распреде- ления и использования прибыли состоит из следующих этапов [1; 4; 9; 20]. Этап 1. Анализ состава, динамики и формирования чистой прибыли. Этап 2. Проведение факторного анализа прибыли (убытка) от продаж. Этап 3. Выявление причин отклонений по основным составляющим прибыли, величина которых может быть спланирована (проценты к получению, проценты к уплате, доходы от участия в других организациях, налог на имущество). Этап 4. Анализ формирования чистой прибыли и влияния налога на прибыль, суммы иных налоговых перечислений в бюджет (обязательные налоги). Этап 5. Факторный анализ затрат, объема продаж и прибыли. Этап 6. Анализ использования прибыли и оценка эффективности ее распределения. Этап 7. Разработка предложений по повышению доходов и оптимизации расходов. Анализом финансовых результатов занимаются не только топ-руководители и профильные службы организации, но и его учредители, инвесторы с целью изучения эффективности использования ресурсов, банки для оценки условий кредитования и определения степени риска, поставщики для своевременного получения платежей, налоговые инспекции для выполнения плана поступления средств в бюджет и т. д. [10]. В табл. 6 обобщены пользователи и их основные экономические интересы.

В заключение отметим, выбор конкретной системы показателей анализа финансовых результатов должен определяться потребностями заинтересованных пользователей и составом информационной базы $[10 ; 11]$. Аналитик должен иметь однозначное, четкое представление о порядке образования доходов и расходов организации, так как они являются ключевыми элементами при определении финансовых результатов. Далее анализируются причины изменения конечного финансового результата, стабильные и случайные факторы, повлиявшие на его изменение. Затем проводится углубленный анализ финансовых результатов с привлечением данных управленческого учета, раскрывающих информацию о доходах и расходах в разрезе центров ответственности. В конце формируются предложения по повышению эффективности финансовых результатов, выявляются существующие резервы и направления улучшения их использования. 
Информационно-аналитическое обеспечение управления финансовыми результатами...

Т а бл и ц а 6

Пользователи анализа финансовых результатов и их интересы

\begin{tabular}{|c|c|c|}
\hline Пользователи & Интересы & Источники и результаты анализа \\
\hline \multicolumn{3}{|c|}{ Внешние пользователи } \\
\hline Акционеры & $\begin{array}{l}\text { Оценка степени рискованности инве- } \\
\text { стиций; оценка перспектив выплаты } \\
\text { дивидендов; расчет рыночной стои- } \\
\text { мости акций }\end{array}$ & $\begin{array}{l}\text { Внешняя финансовая отчетность. Ана- } \\
\text { лиз рентабельности продукции, сегмен- } \\
\text { тов, динамика чистой прибыли, изме- } \\
\text { нение расходов }\end{array}$ \\
\hline Инвесторы & $\begin{array}{l}\text { Экономическая стабильность органи- } \\
\text { зации, расчет доходности направле- } \\
\text { ний деятельности, окупаемость инве- } \\
\text { стиций, проекты, динамика прибыли }\end{array}$ & $\begin{array}{l}\text { Внешняя бухгалтерская (финансовая) от- } \\
\text { четность. Отчет об устойчивом развитии, } \\
\text { ключевые показатели эффективности }\end{array}$ \\
\hline $\begin{array}{l}\text { Кредитные } \\
\text { организации }\end{array}$ & $\begin{array}{l}\text { Кредитоспособность, платежеспособ- } \\
\text { ность и ликвидность, чистая прибыль }\end{array}$ & $\begin{array}{l}\text { Внешняя отчетность. Коэффициентный } \\
\text { и факторный анализ финансовых резуль- } \\
\text { татов }\end{array}$ \\
\hline $\begin{array}{c}\text { Проверяющие } \\
\text { и контролирую- } \\
\text { щие организации } \\
\text { (налоговая инспек- } \\
\text { ция, иные) }\end{array}$ & $\begin{array}{l}\text { Оценка правильности исчисления } \\
\text { налогооблагаемой базы, законности } \\
\text { операций и признания доходов, рас- } \\
\text { ходов и финансовых результатов }\end{array}$ & $\begin{array}{l}\text { Внешняя финансовая отчетность; нало- } \\
\text { говая отчетность; данные внутренних и } \\
\text { внешних аудиторских проверок }\end{array}$ \\
\hline Кредиторы & $\begin{array}{l}\text { Деловая репутация; оценка надежно- } \\
\text { сти возврата кредита (займа) }\end{array}$ & $\begin{array}{l}\text { Внешняя финансовая отчетность; специ- } \\
\text { альные справки. Финансовая устойчи- } \\
\text { вость, ликвидность баланса, платежеспо- } \\
\text { собность, стабильность прибыли }\end{array}$ \\
\hline Поставщики & $\begin{array}{l}\text { Определения наличия ресурсов для } \\
\text { оплаты поставок; надежность контра- } \\
\text { гента и перспективы сотрудничества }\end{array}$ & $\begin{array}{l}\text { Внешняя финансовая отчетность. Резуль- } \\
\text { таты деятельности и их динамика }\end{array}$ \\
\hline Покупатели & $\begin{array}{l}\text { Деловая репутация, ценовая полити- } \\
\text { ка, качество продукции }\end{array}$ & $\begin{array}{l}\text { Внешняя финансовая отчетность и } \\
\text { специальные отчеты (рейтинги). Ка- } \\
\text { чество сервисного обслуживания, про- } \\
\text { дукции, стабильность работы, ценовая } \\
\text { политика }\end{array}$ \\
\hline Конкуренты & $\begin{array}{l}\text { Ассортиментная и ценовая политика, } \\
\text { доля на рынке и динамика прибыли }\end{array}$ & $\begin{array}{l}\text { Внешняя отчетность, специализирован- } \\
\text { ные отчеты. Выборочный анализ }\end{array}$ \\
\hline \multicolumn{3}{|c|}{ Внутренние пользователи } \\
\hline $\begin{array}{c}\text { Топ-менеджмент } \\
\text { организации }\end{array}$ & $\begin{array}{l}\text { Наличие чистой прибыли в компа- } \\
\text { нии и по видам деятельности, регио- } \\
\text { нам, подразделениям, продуктам }\end{array}$ & $\begin{array}{l}\text { Внешняя и внутренняя отчетность, } \\
\text { специальные доклады, презентации и } \\
\text { сводные отчеты. Анализ рентабельно- } \\
\text { сти, эффективности и исполнения клю- } \\
\text { чевых показателей }\end{array}$ \\
\hline $\begin{array}{c}\text { Менеджеры } \\
\text { среднего и } \\
\text { низшего звена }\end{array}$ & $\begin{array}{l}\text { Доля продукции с высокой маржи- } \\
\text { нальностью. Оценка эффективности, } \\
\text { доходности и прибыльности в разре-- } \\
\text { зе зон ответственности }\end{array}$ & $\begin{array}{l}\text { Внутренние отчеты; управленческая } \\
\text { отчетность. Расширенный анализ и экс- } \\
\text { пресс-мониторинг для принятия управ- } \\
\text { ленческих решений об увеличении } \\
\text { ассортимента, вывода нерентабельных } \\
\text { направлений и др. }\end{array}$ \\
\hline $\begin{array}{c}\text { Сотрудники } \\
\text { компании }\end{array}$ & $\begin{array}{l}\text { Стабильность работы компании, дина- } \\
\text { мика прибыли, платежеспособности }\end{array}$ & $\begin{array}{l}\text { Внешняя и внутренняя информация в } \\
\text { соответствии с интересами: прибыль, } \\
\text { расходы на заработную плату, социаль- } \\
\text { ные гарантии }\end{array}$ \\
\hline
\end{tabular}




\section{Обсуждение результатов}

Поддержка на государственном уровне использования передовых технологий, преимущественно направленных на обеспечение экологический устойчивости, рациональное и эффективное использование ресурсов, обеспечение социальных гарантий сотрудникам, а также конкурентные отношения на рынках обеспечивают высокий интерес субъектов экономической деятельности к исследованию вопросов управления доходами, расходами и финансовыми результатами, построению системы аналитических показателей и организации экономического анализа таким образом, чтобы обеспечить принятие взвешенных управленческих решений в оперативном порядке и в случае необходимости минимизировать риски. Во многом эффективность производственной, инвестиционной и финансовой деятельности организации определяется объемом достигнутых положительных финансовых результатов, а взвешенный подход к решению задач по росту доходной составляющей и оптимизации расходной составляющей является фундаментом для реализации ее стратегических целей. Достижение компанией прибыли зависит как от внешних факторов (экономической ситуации в стране, конкурентных событий, структуры рынка), так и от наличия способностей самой компании организовать деятельность максимально эффективно.

В связи с этим ключевые аспекты исследования проходили обсуждение на научно-практических международных конференциях, курируемых Воронежским государственным университетом. Тематика конференций предусматривала рассмотрение наиболее актуальных вопросов в области учета, анализа и финансово-хозяйственного контроля. В процессе научного обсуждения нами были подняты вопросы, связанные с содержанием и критериями признания доходов, расходов и финансовых результатов, характеристикой информационной базы, приведена систематизация этапов анализа, обобщены внешние и внутренние пользователи его результатов, обозначены их интересы. По результатам конференций озвучены замечания и практические предложения, ценные для дальнейшего исследования в рамках заявленной темы.

\section{Заключение}

Экономическая ситуация на рынках неоднозначна, так как для одних сегментов рынка практически не представляется возможным ведение деятельности вне конкурентных отношений, для других игроки известны и среди них выделяют лидеры с четкой стратегией или отсутствуют в силу специфики рынка (например, отрасли с исторической естественной монополией).

Прибыль является основным финансовым результатом деятельности организации, показывает выраженный в денежной форме чистый доход компании на вложенный собственниками капитал и характеризующий награду за предпринимательских риск финансово-хозяйственной деятельности. Ежегодное наличие положительного финансового результата приводит к непрерывному росту прибыли и создает стабильный фундамент для реализации новых концепций роста и развития, внедрения новых проектов, обеспечения социальной основы работников и интересов собственников. За счет прибыли выполняются обязательства организации перед государством, пополняются специальные фонды и резервный капитал. Показатели прибыли являются важнейшими в системе оценки результативности организации, степени финансового благополучия и надежности как партнера.

Следует также подчеркнуть, что убытки играют определенную роль в жизни организации, позволяют увидеть ошибки менеджмента экономического субъекта в направлениях получения финансовых результатов, научиться управлять финансовыми и нефинансовыми рисками.

В связи с этим понимание природы формирования финансовых результатов, его компонентов, максимально эффективное использование материально-вещественных потоков, поиск резервов роста доходов по обычным и прочим видам деятельности позволит своевременно и взвешенно принимать управленческие решения в отношении финансовых результатов в текущей и перспективной деятельности.

Приведенные в статье подходы к содержанию финансовых результатов позволяют увидеть нормативный и авторские подходы, способствующие формированию комплексного видения, систематизация информационных источников позволяет выявить комплексно базу для проведения экономического анализа 
Информационно-аналитическое обеспечение управления финансовыми результатами...

в соответствии с потребностями пользователей и конкретными задачами анализа. Приведенная классификация интересов пользователей отличается практико-ориентированным подходом. Во многих источниках можно встретить общее понимание, что экономический анализ финансовых результатов строится на данных публичной отчетности, однако ряд показателей может быть рассчитан с использованием управленческих данных. Мы рассмотрели комплексный подход к содержанию финансовых результатов и составу аналитического обеспечения для принятия управленческих решений. В отношении экономического анализа финансовых результатов подчеркнем, что объемы и степень его детализации должны определяться потребностями конкретных пользователей. В сжатые сроки принятия управленческого решения, затрагивающего взаимодействие с контрагентом, банком и использование финансовых и нефинансовых ресурсов, целесообразно проводить экспресс-анализ, в то время как на основе обобщающих выводов по результатам работы за квартал или год проводить полную оценку факторов, оказавших влияние на финансовые результаты для управления в будущем. Убеждены, превентивные меры по мониторингу доходов и расходов по видам деятельности, отдельным продуктам, регионам в течение года позволят достичь желаемой цели экономической деятельности любой коммерческой организации - чистой прибыли. Руко-

\section{Библиографический список}

1. Бариленко В. И. Анализ финансовой отчетности / В. И. Бариленко. - Москва : Кнорус, 2016.

2. Борисов Е. Ф. Экономическая теория / Е. Ф.Борисов. - Москва : Проспект, 2012.

3. Бреславцева Н. А. Бухгалтерский учет/ Н. А. Бреславцева, Н. В. Михайлова, О. Н. Гончаренко. - Москва : Феникс, 2013.

4. Гиляровская Л. Т. Комплексный экономический анализ хозяйственной деятельности / Л. Т. Гиляровская. - Москва : ТК Велби, 2008.

5. Ендовицкий Д. А. Корпоративный анализ / Д. А. Ендовицкий, Л. С. Коробейникова, И. В. Полухина. - Москва : Юрайт, 2019.

6. Ендовицкий Д. А. Учет, анализ и контроль в корпорациях / Д. А. Ендовицкий. - Воронеж : Издательский дом ВГУ, 2018.

7. Ефимова О. В. Финансовый анализ : современный инструментарий для принятия экономических решений / О. В. Ефимова. - Москва : Омега-Л, 2009. водство должно быть более дальновидным, стратегически смотреть на развитие организации и вне зависимости от своего положения на рынке максимально эффективно и экономно использовать имеющиеся ресурсы, работать над поиском новых инструментов повышения эффективности хозяйствования. Финансовые результаты во многом являются измерителем конечной результативности и эффективности всех предпринятых руководством действий, направленных на достижение прибыли. Перспективным направлением к дальнейшему научному исследованию считаем разработку комплексной методики анализа финансовых результатов экономического субъекта, которая позволит, опираясь на ведущие разработки ученых-экономистов и потребность реального бизнеса, сформировать информационное, организационное и методическое обеспечение анализа доходов, расходов и финансовых результатов от обычной и прочих видов деятельности. Это позволит повысить оперативность проведения экономического анализа в данном направлении в организации, качество управленческих решений, принимаемых на основе полученных заключений и финансово-экономических расчетов.

\section{Конфликт интересов}

Авторы декларируют отсутствие явных и потенциальных конфликтов интересов, связанных с публикацией настоящей статьи.

8. Камышанов П. И. Практическое пособие по аудиту / П. И. Камышанов. - Москва : ИНФРА-М, 2012.

9. Ковалев В. В. Управление финансовой структурой фирмы / В. В. Ковалев. - Москва : Проспект, 2018.

10. Полухина И. В. Экономический анализ резервов повышения конкурентной устойчивости и эффективности деятельности коммерческой организации / И. В. Полухина // Современная экономика : проблемы и решения. - 2019. - № 6 (114). C. $125-148$.

11. Полухина И. В. Финансовая устойчивость как гарант конкурентоспособности / И. В. Полухина // Современная экономика : проблемы и решения. 2017. - № 3 (87). - C. 81-98.

12. Савицкая Г. В. Анализ хозяйственной деятельности предприятия / Г. В. Савицкая. - Москва : ИНФРА-М, 2013. - 288 с.

13. Сапожникова Н. Г. Бухгалтерский учет и отчётность / Н. Г. Сапожникова, И. В. Панина, 
О. Н. Гальчина, Л.С. Коробейникова. - Москва : Кнорус, 2015. - 360 с.

14. Селезнева Н. Н. Финансовый анализ / Н. Н. Селезнева, А. Ф. Ионова. - Москва : Проспект, 2012. - 624 c.

15. Сурин А. Н. История экономики и экономических учений / А. Н. Сурин. - Москва : Финансы и статистика, 2011. - 200 с.

16. Чая В. Т. Международные стандарты финансовой отчетности / В. Т. Чая, Г. Т. Чая. - Москва : Юрайт, 2015. - 432 с.
17. Шапкин А. С. Экономические и финансовые риски. Оценка, управление, портфель инвестиций / А. С. Шапкин. - Москва : Дашков и К, 2010. - 544 c.

18. Шеремет А. Д. Финансы предприятий / А. Д. Шеремет, Р. С. Сайфулин. - Москва : ИНФРА-М, 2008. - 343 c.

19. Шеремет А. Д. Методика финансового анализа / А. Д. Шеремет. - Москва : ИНФРА-М, 2016.

20. Шредер Н. Г. Анализ финансовой отчетности / Н. Г. Шредер. - Москва : Альфа-Пресс, 2017.
Полухина Ирина Валерьевна, кандидат экономических наук, доцент кафедры экономического анализа и аудита, Воронежский государственный университет, Воронеж, Российская Федерация

E-mail: ivp_87@mail.ru

ORCID ID: 0000-0002-8770-2624
Поступила в редакцию 09.03.2020

Подписана в печать 05.04.2020 


\title{
Information and analytical support for financial results management in companies
}

\section{V. Polukhina ${ }^{1 凶}$}

\author{
${ }^{1}$ Voronezh State University, 1, University sq., 394018, Voronezh, Russian Federation
}

Cite as: Polukhina, I. V. (2020). Information and analytical support for financial results management in companies. Proceedings of Voronezh State University. Series: Economics and Management. 2, 90-104. (In Russ., abstract in Eng.) DOI: 10.17308/econ.2020.2/2904

Importance. Financial results are a significant indicator in the assessment of efficiency of financial and
economic activity, make it possible to assess the extent to which risks accepted by the company have
been justified, profit creates a financial basis for the development of the organization, ensuring market
competitiveness, realization of opportunities for fulfillment of social corporate obligations to employees
and increase of business value in the interests of its owners. Timely analysis of revenues, expenses and
factor-by-factor assessment of financial results will make it possible in the present conditions to make
balanced management decisions aimed at maximizing the revenue and minimization of the expenditure
component in order to ensure the company's success. Objectives. A comprehensive author 's study of the problem of analyzing the financial results of a commercial organization, which acts as a guarantor of ensuring the long-term development of the organization in the market, an integral component of sustainability and a key area in the system of integrated economic analysis of activities.

Methods. The author reveals the meaning and content of financial results and its components, conducts a comparative analysis of approaches to the essence, systematizes the information base using the accumulated practical experience. Competent and targeted analytical support for sound management decisions on the use of financial and non-financial resources would ensure the desired performance. The study of the problem used methods of logical, comparative analysis, search and systematization.

Results. The author discloses theoretical aspects of analysis of financial results, provides comparative analysis of the essence of financial results, systematized information and regulatory sources, disclosed their content and peculiarities of application in practice, generalized economic interests of users.

Conclusions and Relevance. It was concluded that the achievement of the positive financial result (profit) is the central direction of the top management of the organization and the result of successful current, investment and financial activities. However, in competition, the organization is not immune from receiving losses. They show management mistakes and misses in the use of mother-alphysical and monetary assets. In this regard, sound management of income and expenditure is of particular importance. The quality of the information base directly depends on the reliability of the analytical conclusions underlying the adoption of balanced management decisions. When analyzing financial results, it is essential to take into account the economic interests of users interested in the results. This would allow for the selection of a group of key performance indicators for the Organization and the optimal allocation of resources.

Key words: income and expenses, profit (loss), efficiency, company’s stability, financial analysis.

\section{Conflict of Interest}

The authors declare that there are no obvious or potential conflicts of interest associated with the publication of this article.

\section{References}

1. Barilenko, V. I. (2016) Analiz finansovoi otchetnosti [Analysis of financial reporting]. Moscow. Knorus. (In Russ.)

2. Borisov, E. F. (2012) Ekonomicheskaia teoryia [Economic theory]. Moscow. Prospekt. (In Russ.)
3. Breslavtseva, N. A., Mihaylova, N. V. \& Goncharenko, O. N. (2013) Buhgalterskiy uchet [Accounting]. Moscow. Feniks. (In Russ.)

4. Gilyarovskaya, L. T. (2008) Kompleksnyi ekonomicheskiy analiz hozyajstvennoy deyatelnosti [Complex analysis of companies activities]. Moscow. TK Velbi.(In Russ.) 
5. Endovitsky, D. A., Korobeinikova, L. S. \& Poluhina, I. V. (2019) Korporativniy analiz [Corporate analysis]. Moscow. Urait. (In Russ.)

6. Endovitsky, D. A. (2018) Uchet, analiz i kontrol v korporatsiyah [Accounting, analysis and audit in corporation]. Voronezh. Voronezh St. Univ. Publ. (In Russ.)

7. Efimova, O. V. (2009) Finansovyi analiz: sovremennyi instrumentarii dlya prinyatiya ekonomicheskih resheniy [Finance analysis: modern tool for taking management decisions]. Moscow. Omega-L. (In Russ.)

8. Kamyshanov, P. I. (2012) Prakticheskoe posobie po auditu [Practical manual about audit]. Moscow. Infra-M. (In Russ.)

9. Kovalev, V. V. (2018) Upravlenie finansovoy strukturoy firmy [Management of financial firm structure]. Moscow, Prospekt. (In Russ.)

10. Poluhina, I. V. (2019) Ekonomicheskii analiz rezervov povysheniya konkurentnoi ustoychivosti i effektivnosti deyatelnosti kommercheskoi organizatsii [Economic analysis of reserves for increasing competitive efficiency and efficiency of organization]. Modern Economics: Problems and Solutions, 6(114), 125-148. (In Russ.)

11. Poluhina, I. V. (2017) Finansovaya ustoichivost kak garant konkurentosposobnosti [Financial stability as guarantor of company competiveness]. Modern Economics: Problems and Solutions, 3 (87), 81-98. (In Russ.)
12. Savitskaya, G. V. (2013) Analiz hozyajstvennoi deyatelnosti predpriyatiya [Economic analysis]. Moscow. Infra-M. (In Russ.)

13. Sapozhnikova, N. G., Panina, I. V., Galchina, O. N. \& Korobeinikova, L. S. (2015) Buhgalterskij uchet $i$ otchjotnost [Accounting and reporting]. Moscow. Knorus. (In Russ.)

14. Selezneva, N. N. \& Ionova, A. F. (2012) Finansovyi analiz [Financial analysis]. Moscow. Prospekt. (In Russ.)

15. Surin, A. N. (2011) Istoriya ekonomiki i ekonomicheskih uchenij [History of economic exercises]. Moscow. Finansy i statistika. (In Russ.)

16. Chaya,V.T. \& Chaya, G.T.(2015) Mezhdunarodnye standarty finansovoj otchetnosti [International standards of financial reporting]. Moscow. Urait, 2015. (In Russ.)

17. Shapkin,A. S. (2010) Ekonomicheskie i finansovye riski. Otsenka, upravlenie, portfel investitsij [Economic and financial risks. Evaluation, management, portfolio of investments.]. Moscow. Dashkov i K. (In Russ.)

18. Sheremet, A. D. \& Sayfulin, R. S. (2008) Finansy predpriyatij [Finance]. Moscow. Infra-M. (In Russ.)

19. Sheremet, A. D. \& Sayfulin, R. S. (2016) Metodika finansovogo analiza [Financial analytical methods]. Moscow. Infra-M. (In Russ.)

20. Shreder, N. G. (2017) Analiz finansovoj otchetnosti [Financial reporting analysis]. Moscow. Alfa-Press. (In Russ.)
Irina V. Polukhina, Cand. Sci. (Econ), Assoc. Prof., Economic analysis and audit, Voronezh State University, Voronezh, Russian Federation E-mail: ivp_87@mail.ru

ORCID ID: 0000-0002-8770-2624
Received 09.03.2020

Accepted 05.04.2020 